\title{
Evapotranspiration and its main controlling mechanism over the desert riparian forests in the lower Tarim River Basin
}

\author{
YUAN GuoFu ${ }^{1 *}$, LUO $\mathrm{Yi}^{1}$, SHAO MingAn ${ }^{1}$, ZHANG Pei ${ }^{1,2} \&$ ZHU XuChao ${ }^{1,2}$ \\ ${ }^{1}$ Key Laboratory of Ecosystem Network Observation and Modeling, Institute of Geographical Sciences and \\ Natural Resources Research, Chinese Academy of Sciences, Beijing 100101, China; \\ ${ }^{2}$ College of Resources and Environment, University of Chinese Academy of Sciences, Beijing 100049, China
}

Received April 10, 2014; accepted December 17, 2014; published online April 13, 2015

\begin{abstract}
Evapotranspiration (ET) and its controlling mechanism over the desert riparian forests in arid regions are the important scientific basis for the water resources managements of the lower reaches of the inland rivers of China. Nearly three years of continuous measurements of surface ET, soil water content at different depths and groundwater table over a typical Tamarix spp. stand and a typical Populus euphratica stand were conducted in the lower reach of the Tarim River. The ET seasonal trends in the growing season were controlled by plant phenology, and ET in non-growing season was weak. The diurnal variations of ET resulting from the comprehensive effects of all atmospheric factors were significantly related with reference ET. The spatial pattern of ET was determined by vegetation LAI, more vegetation coverage, more ET amount. Groundwater is the water source of surface ET, and the soil water in shallow layers hardly took part in the water exchange in the groundwatersoil-plant-air system. The temporal processes of ET over the Tamarix stand and the Populus stand were similar, but the water consumption of the well-grown Populus euphratica was higher than that of the well-grown Tamarix spp. Further analysis indicates that plant transpiration accounts for most of the surface ET, with soil evaporation weak and negligible; groundwater table is a crucial factor influencing ET over the desert riparian forests, groundwater influences the processes and amounts of ET by controlling the growth and spatial distribution of desert riparian forests; quantifying the water stress of desert riparian forests using groundwater table is more appropriate, rather than soil water content. Based on the understanding of ET and water movements in the groundwater-soil-plant-air system, a generalized framework expressing the water cycling and its key controlling mechanism in the lower reaches of the inland rivers of China is described, and a simple model to estimate water requirements of the desert riparian forests is presented.
\end{abstract}

lower reaches of the Tarim River, water cycling, evapotranspiration, desert riparian forests, Tamarix spp., Populus euphratica

Citation: Yuan G F, Luo Y, Shao M A, et al. 2015. Evapotranspiration and its main controlling mechanism over the desert riparian forests in the lower Tarim River Basin. Science China: Earth Sciences, 58: 1032-1042, doi: 10.1007/s11430-014-5045-7

The inland rivers are the main source of water resources in arid northwestern China. Revealing the water cycling processes of these inland rivers and their controlling mechanism is an important scientific basis for managing water resources in the arid northwestern China. The attention of

*Corresponding author (email: yuangf@igsnrr.ac.cn) the relevant researches generally focused on the upper and middle reaches of these inland rivers because the upper reaches are the areas of producing water resource, and the middle reaches are the main water consuming area for human beings. However, less attention has been given to the researches on the water cycling in the lower reaches of these inland rivers, including the exchanges between river water and groundwater, the water movements in the groundwa- 
ter-soil-plant-air system and the surface evapotranspiration (ET) processes. In the lower reaches of these inland rivers, the long and narrow riparian forests along the rivers usually develop, and it is important for managing the environment and controlling the desertification in the lower reaches (Shi, 2004). In the lower reaches of the Tarim River, which is the longest inland river of China, the desert riparian forests zone is also called "Green Corridors" (Fang, 2001), which ensures the transportation between the northern and southern areas of the Tarim Basin. The understanding of the water cycling processes and its influencing factors of the lower reaches of the inland rivers, especially of the desert riparian forests, can help quantify the water consumptions and water requirements of the desert riparian forests, understand the maintaining mechanisms of the desert riparian forests, improve the water resource management of these inland rivers, and enhance the ability of controlling desertification in arid region of China.

The previous relevant researches on hydrology and water resources in the lower reaches of the inland rivers of China were mainly conducted at two aspects. One was interested in the hydrological controls of the desert riparian forests, mainly exploring the relationships between groundwater and vegetations, from leaf scale to communities level (Chen et al., 2003, 2006; Hao et al., 2008, 2010; Zhang et al., 2011; Zhu et al., 2012; Wang et al., 2014; Li et al., 2008, 2013). The other attempted to estimate ecological water requirements of the desert riparian forests for the water resource management (Wang et al., 2002, 2005; Liu, 2004; Ye et al., 2007; Chen et al., 2007; Chen et al., 2008a). Most researches focused on the ecophysiological and ecohydrological processes, but the hydrological processes, particularly the water movements and ET over the desert riparian forest zone, have received little study.

All of the lower reaches of the inland rivers in China are located in hyper-arid regions with scarce precipitation. The water cycling process in the lower reaches can be simply characterized as a process of the water movement from the river water to groundwater, and then to the surface ET, in which the water movement in the groundwater-soil-plant-air system is one of the critical processes controlling the water cycling in the lower reaches. In addition, the desert riparian forests are one of the most valuable landscapes in the lower reaches. ET over the desert riparian forests is the main form of water resources consumptions in these regions. Therefore, revealing the characteristic of water movements and ET in the groundwater-soil-plant-air system can help understand the water cycling processes and their critical controlling mechanisms in the lower reaches of the inland rivers of China.

In this study, we selected a well-grown Tamarix spp. stand and a well-grown Populus euphratica stand in the lower reach of the Tarim River to conduct our field observations. Based on the eddy covariance (EC) method, the carbon and vapor fluxes, energy balance, radiation balance, soil water content at different depths and groundwater table were measured concurrently in the last three years. In this paper, we focus mainly on the water movement in the groundwater-soil-plant-air system and ET over the Tamarix stand and the Populus stand. Our objective is to reveal ET temporal and spatial processes and their controlling mechanisms. These results will improve our understanding of water cycling processes in the lower reaches of the inland rivers of China, and provide new scientific ideas for managing water resources and desertification control in these regions.

\section{Materials and methods}

\subsection{Site descriptions}

The lower reach of the Tarim River are located between the Taklamagan Desert and Kuluk Desert, from the Daxihaizi reservoir to the terminal Taitmar Lake with a length of approximately $250 \mathrm{~km}$ (Chen et al., 2004). This region is located in the typical continental temperate hyper-arid climate zone. According to the meteorological records of the Tieganlik Weather Station, located in the lower Tarim River Basin, the average annual temperature is $10.7^{\circ} \mathrm{C}$, annual accumulated temperature is $4167.7^{\circ} \mathrm{C}$, annual total solar radiation is $6180 \mathrm{MJ} \mathrm{m}^{-2}$, annual sunshine number is about $3118.7 \mathrm{~h}$, with 220 frost-free days. The mean annual precipitation was $33.7 \mathrm{~mm}$ from 1957 to 2012; however, the annual potential evapotranspiration can reach more than 2000 $\mathrm{mm}$ (Chen et al., 2006). The plant communities in this area can mainly be classified into two categories: Populus (Populus euphratica) forest and Tamarix (Tamarix spp.) forest. Populus forest belongs to arbor forest and Tamarix forest belongs to shrub forest. The species richness in the plant communities is low. The coverage of community in this area is also low due to poor water condition (Chen, 2010).

Two typical and well-grown riparian forests were chosen to conduct our field observation (Figure 1). The Populus forest is located at $40^{\circ} 25^{\prime} 59^{\prime \prime} \mathrm{N}, 88^{\circ} 01^{\prime} 34^{\prime \prime} \mathrm{E}$, with an altitude of $844 \mathrm{~m}$, and the Tamarix stand located at $40^{\circ} 25^{\prime} 59^{\prime \prime} \mathrm{N}, 88^{\circ} 01^{\prime} 34^{\prime \prime} \mathrm{E}$, with an altitude of $846 \mathrm{~m}$.

The Tamarix stand chosen for observation covers an area of approximately $300 \mathrm{~m} \times 300 \mathrm{~m}$. The dominant species in the stand are Tamarix ramosissima, Tamarix hispida and Tamarix elongata. Small amounts of other shrubs and herbs, such as Lycium ruthenicum, Halimodendron halodendron, Phragmites australis, Apocynum venetum, Alhagi sparsifolia, Karelinia caspica, Glycyrrhiza inflata, grow in the communities. The Simpson diversity index of the observation site is 0.71 , the vegetation cover is 0.65 , and the leaf area index (LAI) measured by LAI-2250 (Li-cor, Nebraska USA) is 1.15 . The soil of the observation site is predominately silt loam with approximately $20 \mathrm{~cm}$ of a dry sand surface layer. The average soil bulk density is approximately $1.3 \mathrm{~g} \mathrm{~cm}^{-3}$. The depth of the water table (DWT) fluctuates around $6 \mathrm{~m}$. 


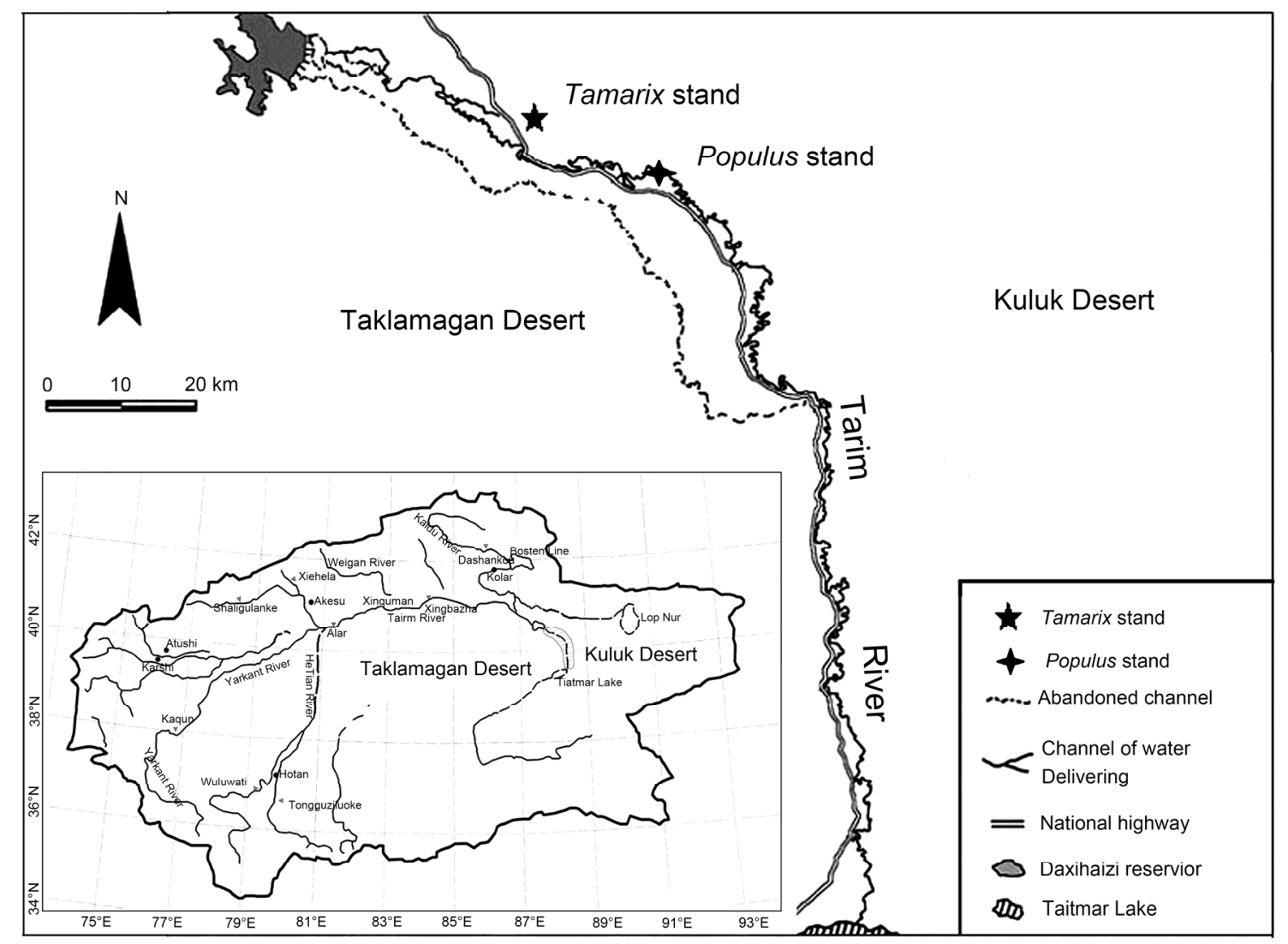

Figure 1 Locations of the observation stands in the lower reach of the Tarim River.

The Populus stand chosen to observe stretches along the river for about $1.5 \mathrm{~km}$, with a width of about $500 \mathrm{~m}$. The canopy height here is about $10 \mathrm{~m}$. Besides some pieces of reed spreading along the river bank, the Populus euphratica is the only species in the observation area. The forest is well grown, with 0.49 coverage rate. The leaf area index observed by LAI-2250 canopy analyzer is 0.57 . The soil texture in root layer is slightly complex, and at depths of $0-3$ $\mathrm{m}$, soil is silt loam, while below $3 \mathrm{~m}$, soil is sandy. The DWT fluctuates around $3.8 \mathrm{~m}$.

\subsection{Observation and data processing}

\subsubsection{Flux measurements and data processing}

Two EC observation towers were used to measure fluxes of momentum, sensible heat $(H)$ and latent heat $(L E)$ in Populus stand and Tamarix stand, respectively. The core flux instrumentation consists of a high-frequency $(10 \mathrm{~Hz} \mathrm{sam}-$ pling with a 30-min integration period) sonic anemometer (CSAT3, Campbell Scientific, USA), and an open-path infrared $\mathrm{H}_{2} \mathrm{O} / \mathrm{CO}_{2}$ gas analyzer (EC150, Campbell Scientific, USA) to measure momentum, heat, vapor and $\mathrm{CO}_{2}$ flux. Both wind speed and gas concentration measurements and their fluctuations were obtained at a frequency of $10 \mathrm{~Hz}$. Down- and up-welling long- and short-wave radiation were measured using a CNR4 net radiometer (Kipp \& Zonen,
Delft, Netherlands). Two heat flux plates (HFP01-L, Campbell Scientific, USA) were buried $0.08 \mathrm{~m}$ below the surface to measure the soil heat flux. Four thermocouple temperature sensors (109, Campbell Scientific, USA) were buried in the upper $0.02 \mathrm{~m}$ and $0.06 \mathrm{~m}$. A datalogger (CR3000, Campbell Scientific, USA) was used for raw data collection and online flux data preliminary processing. The sonic anemometer and the gas analyzer were set at $1.8 \mathrm{~m}$ above the canopy for Tamarix stand and $5 \mathrm{~m}$ for Populus stand. The CNR4 net radiometer was set at $1.5 \mathrm{~m}$ above the canopy for Tamarix stand and $3.5 \mathrm{~m}$ for Populus stand.

The EdiRe software (School of Geosciences, University of Edinburgh) was used for the post-processing of the EC data, including spectral correction, coordinate rotation density correction and gap filling. The half-hourly turbulent fluxes and meteorological variables were again screened to remove spurious data points caused by sensor malfunction, rain events, and sensor maintenance. The energy balance was forced to close according to the Bowen ratio (Wohlfahrt et al., 2009) to obtain the sensible heat flux and latent heat flux data.

\subsubsection{Other measurements}

Air temperature and relative humidity were measured at 3.5 m (HMP155A-L, Vaisala, Helsinki Finland) above the ground for Tamarix stand, and $15 \mathrm{~m}$ for Populus stand. An 
automatic rain gauge (52203, RM Young Inc., USA) was placed at an empty plot in the south of the flux tower in the Tamarix stand to record precipitations.

Proximal to the flux tower in Tamarix stand at depths of $0.3,0.6,1.0,1.5,2.0,2.5,3.0,4.0$, and $5.0 \mathrm{~m}$, soil volumetric water content (SWC) was measured every 30 min using 9 frequency domain capacity (FDC) sensors (FDS100, Unism, Beijing, China). The FDC sensors were calibrated at the field in this research.

A 20-m-deep observation well was drilled, $30 \mathrm{~m}$ from the flux tower, and an automatic groundwater table logger (CTD-Diver, Eijkelcamp, EMGiesbeek Netherlands) was placed to record the DWT and water temperature. The DWT was corrected by air pressure measured by the EC system.

All of these factors were measured every $30 \mathrm{~min}$ and recorded by the CR3000 datalogger except that the depth of the water table was recorded by the sensor itself.

\subsubsection{Statistic method}

Statistical analysis of data and the calculation of statistics were conducted using the SigmaPlot v12.3 software (Systat Software Inc. Illinois, USA).

\subsection{Calculations}

\subsubsection{Calculations of ET and reference ET}

Hourly ET was calculated based on the observed hourly $L E$ value. The quality of the EC data in the night is poor because of the weak turbulence, and ET is weak in the night. To reduce the impact of poor quality observation data in the night on the results, the daily ET was the sum of the hourly ET at daytime (PAR $>1 \mathrm{~W} \mathrm{~m}^{-2}$ ). The ET was compared with the reference $\mathrm{ET}\left(\mathrm{ET}_{0}\right)$. The $\mathrm{ET}_{0}$ was calculated from Penman-Monteith equation corrected by FAO (Allen et al., 1998) at daily and hourly scales. The daily weather data used to calculate the daily $\mathrm{ET}_{0}$ were from the Tieganlik Weather Station, and the data used to calculate the hourly $\mathrm{ET}_{0}$ were from the observation at our flux tower.

\subsubsection{Calculation of groundwater evapotranspiration}

Hourly or even higher frequent measurements of the groundwater table are able to reveal the diurnal fluctuation of the groundwater table. Based on the principle of water balance, White et al. (1932) presented a method to estimate the daily groundwater evapotranspiration (ETg) based on the groundwater table diurnal variation, as the following equation:

$$
\mathrm{ETg}=S_{\mathrm{y}}(24 r \pm s),
$$

where ETg is daily groundwater evapotranspiration $\left(\mathrm{mm} \mathrm{d}^{-1}\right)$, $S_{\mathrm{y}}$ is specific yield (dimensionless), $r$ is the groundwater recharge rate $\left(\mathrm{mm} \mathrm{h}^{-1}\right)$, and $s$ is the groundwater storage change, which equals the rise or fall of the groundwater table after $24 \mathrm{~h}$ (downward is positive, $\mathrm{mm} \mathrm{d}^{-1}$ ). Variables $r$ and $s$ are both determined by the $24 \mathrm{~h}$ water table fluctua- tion curve.

$S_{\mathrm{y}}$ is of crucial importance because errors in $S_{\mathrm{y}}$ estimation directly translate to the ETg estimates. In this study, a readily available $S_{\mathrm{y}}$ (Loheide et al., 2005) was selected. The readily available $S_{\mathrm{y}}$ value was determined solely from the soil texture at the depth of the groundwater table. The $S_{\mathrm{y}}$ value used in this study was finely determined based on the soil textures at the depth of the groundwater table in the Tamarix stand using the method presented by Loheide et al. (2005). The $S_{\mathrm{y}}$ value was 0.065. $r$ value was obtained as the slope of the groundwater hydrography during 3-7 a.m. (Beijing time), when the plant root water uptake ceased. The value $s$ is the net fall or rise of the water table in the 24 $\mathrm{h}$ period. In this study, $s$ values were determined from the difference between the two water levels at 0 a.m. today and the subsequent day.

\section{Results}

\subsection{Temporal processes and the control factors of ET}

\subsubsection{Seasonal variation}

Figure 2 shows the seasonal variations of daily ET in 2013 over the Tamarix stand and the Populus stand, and the comparison between the daily ET and corresponding $\mathrm{ET}_{0}$. The day to day variations of ET over the Tamarix stand were consistent with those over the Populus stand in the most time period, and generally consistent with $\mathrm{ET}_{0}$ too. This phenomenon was particularly obvious in the vibrant growing season (VGS), including the vegetative phase, blooming, and fruit ripening stage. In VGS, the correlation between ET and $\mathrm{ET}_{0}$ was high in both the Tamarix stand $\left(R^{2}=\right.$ $0.66)$ and the Populus stand $\left(R^{2}=0.53\right)$ (Figure 3$)$, indicating that integrated weather conditions controlled the daily fluctuations of ET in VGS. However, the seasonal trend of ET change was not consistent with that of $\mathrm{ET}_{0}$ (Figure 2). In the Tamarix stand, the first obvious difference occurred in the germination and leaf expansion period (GLE) (Bai, 1998). During GLE, ET increased gradually with time, but $\mathrm{ET}_{0}$ have fluctuated at a high level in the whole year (Figure 2), suggesting that the influence of the biotic factors on ET was obvious during this period. The second obvious difference occurred in the leaf senescence period (LSP) (Bai, 1998), in which the decreasing rate of ET was bigger than that of $\mathrm{ET}_{0}$. The same phenomenon was also observed in 2011 and 2013 growing season over the Tamarix stand. The different trends of ET and $\mathrm{ET}_{0}$ between different plant phonological stages indicated that ET seasonal variations over the riparian Tamarix stand were significantly affected by the plant phenology. The observation over the Populus stand only covered the VGS and LSP stages. According to available data, the seasonal change trend of ET over the Populus stand showed the same pattern as those over the Tamarix stand (Figure 2). In LSP of the Populus (Figure 2), ET decreased more quickly than $\mathrm{ET}_{0}$, just like that over the Tamarix 


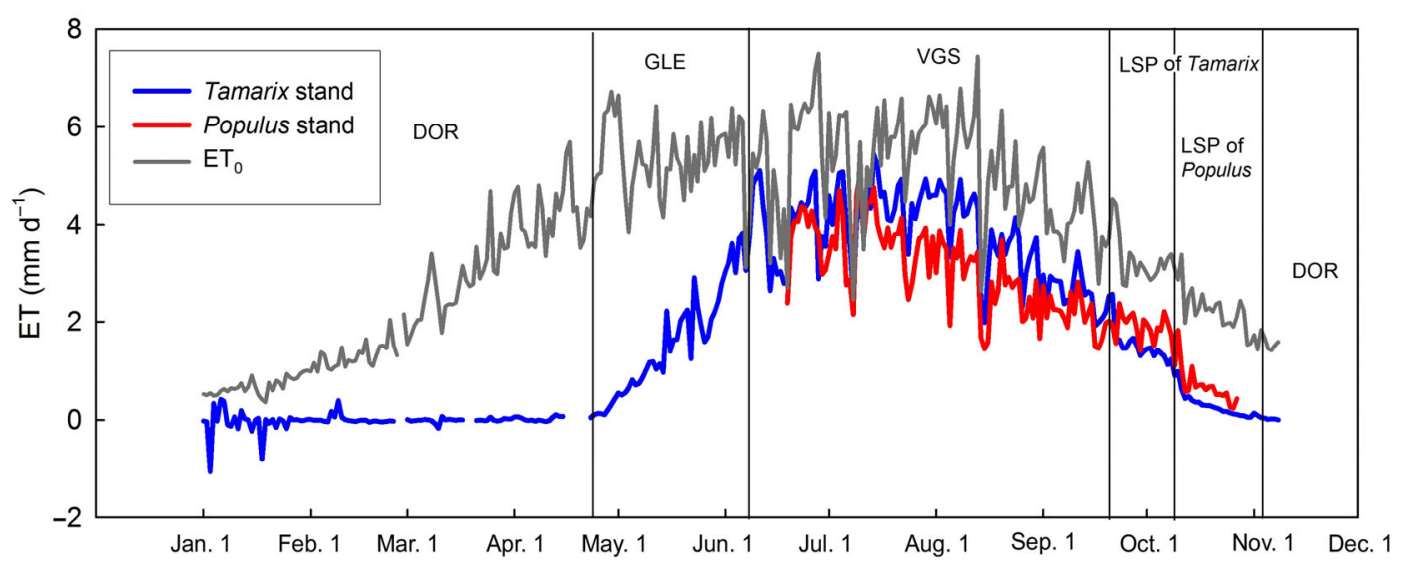

Figure 2 Seasonal variations of daily ET over the Tamarix stand and the Populus stand, and their comparisons with plant phenology and reference evapotranspiration $\left(\mathrm{ET}_{0}\right)$. DOR refers to the dormancy period of plant, GLE refers to the germination and leaf expansion period, VGS refers to the vibrant growing season, and LSP refers to the leaf senescence period.

stand. However, the beginning time of rapid decline of ET over the Populus stand was later than that over the Tamarix stand (Figure 2), which might be due to the delay of the beginning time of the LSP stage of the Populus stage (Abdurahman et al., 2008). The different responses of ET to the LSP stage between the two communicates of Tamarix and Populus further verified the influence of plant phenology on the seasonal variation of ET over the desert riparian forests.

In the non-growing season, namely in the plant dormancy period (DOR), ET was weak, even in March and April, in which $\mathrm{ET}_{0}$ had been high. Obvious ET could be observed only in growing seasoning.

The differences of change trends of ET between different phenological stages and weak ET in DOR indicated that ET over the desert riparian forests was controlled by plant phenology, suggesting that the desert riparian forests play a key role in controlling the water cycling in the lower reaches of the Tarim River. The vegetation coverage of the two

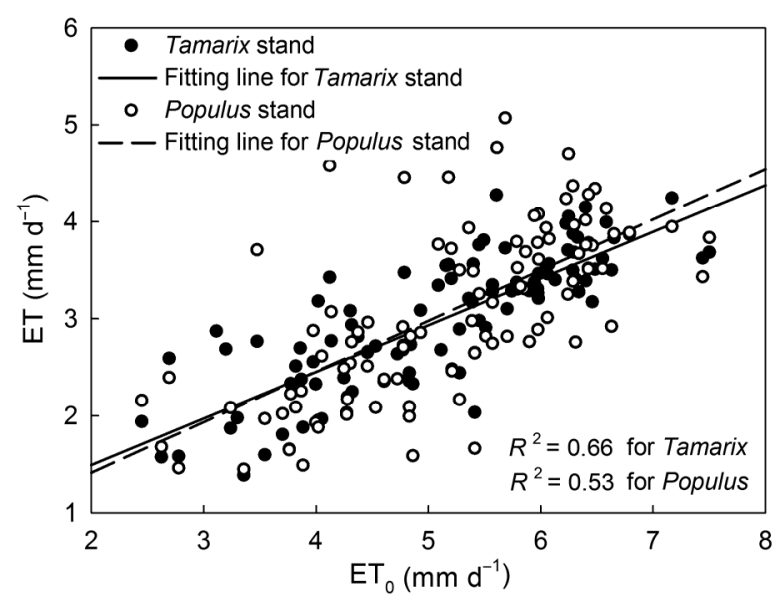

Figure 3 Linear relationships between daily ET and daily $\mathrm{ET}_{0}$ in the vibrant growing seasons over the Tamarix stand and the Populus stand $(P<$ $0.0001)$. observed stands was 0.65 and 0.49 , respectively. Low plant coverage usually means that the soil evaporation would have more contributions to the total surface ET. But the strong correlation between the seasonal variations of ET over the sparse riparian stand and plant phenology suggested the influence of soil evaporation on ET was not obvious, consequently, the contribution of soil evaporation to the total surface ET was weak.

\subsubsection{Diurnal process}

Ten mean days averaging data of hourly ET from July 10 to 19, 2013 expressed 24-h diurnal variations of ET over the riparian forests in VGS (Figure 4). The diurnal processes of hourly ET both over the Populus stand and the Tamarix stand showed a unimodal variation, weak at night, rapidly increased with the sun rising, increased and decrease slowly at a level for most of the daytime (11:00 a.m.-06:00 p.m. Beijing time, 09:00 a.m.-16:00 p.m. local time), and then decreased rapidly after 06:00 p.m. Beijing time (16:00 p.m. local time). However, the shape of the unimodel variation of hourly ET was different between over the Tamarix and Populus stand. The shape of diurnal variation of ET over the Tamarix stand was near triangle, consistent with the solar radiation and air temperature, while the shape over the Populus stand was near trapezoid, suggesting that photosynthesis restraint at noon could exist for Populus euphratica, consequently reducing plant transpiration.

The mean daily ET was $4.52 \mathrm{~mm}$ over the Populus stand, and $5.07 \mathrm{~mm}$ over the Tamarix stand. Considering the vegetation cover and LAI in the Populus stand were significantly less than those in the Tamarix stand, the difference of daily ET amount over between the Populus and Tamarix stand did not indicate that the water consumption of Tamarix spp. was larger than that of Populus euphratica. Instead, if the linear relationship between LAI and ET (see section 3.2) was supposed, the daily ET over a Tamarix stand with the same LAI value of the observed Populus stand 


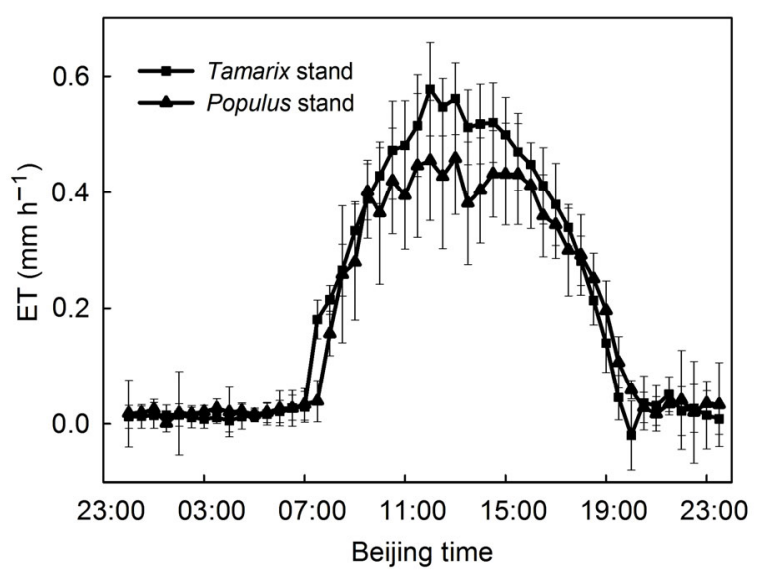

Figure 4 Diurnal processes of hourly ET in the vibrant growing seasons over the Tamarix stand and the Populus stand. The data is obtained by averaging the observation data from 10 to 19 July, 2013. The error bar is the standard error.

would be $2.58 \mathrm{~mm}$, indicating that the water consumption of Populus euphratica was higher than that of Tamarix spp. under the same weather conditions and the same LAI values.

Correlation analysis of main meteorological factors (temperature, humidity, wind speed) and diurnal ET processes showed that diurnal processes were not significantly correlated with any one factor, but significantly correlated with $\mathrm{ET}_{0}$. The correlation coefficient was mostly above 0.9 in the randomly selected days in GLE, VGS and LSP over the Tamarix stand, and the same correlations existed over the Populus stand (Figure 5).

This indicated that the diurnal process of ET was not controlled by any single atmospheric factor, but influenced by integrated atmospheric conditions. This was different with the results observed in the semiarid steppe, where the vapor pressure deficit influenced the diurnal processes of ET significantly (Hao et al., 2007).

\subsection{Key control factors on the spatial variations of ET}

The plant coverage is usually low in the desert riparian forest zone in arid Northwest China, and shows a large spatial variation with the distance from river channel (Chen et al., 2004; Tao et al., 2008; Li et al., 2013). Since the surface ET was obviously under control of the vegetation, the ET values observed over one site could not represent ET characteristics over the whole riparian forest zone due to the large spatial variation of plant coverage. Although the surface ET cannot be measured under all different plant coverages, the control factors of ET spatial variations in the lower reaches of Tarim River under the hyper-arid climate could be assessed according to the observation results.

As mentioned in section 2.1.1, the proportion of the soil evaporation over the desert riparian forests in the total ET is little. This conclusion can be more supported by the comparison of the surface ET before the growing season and the
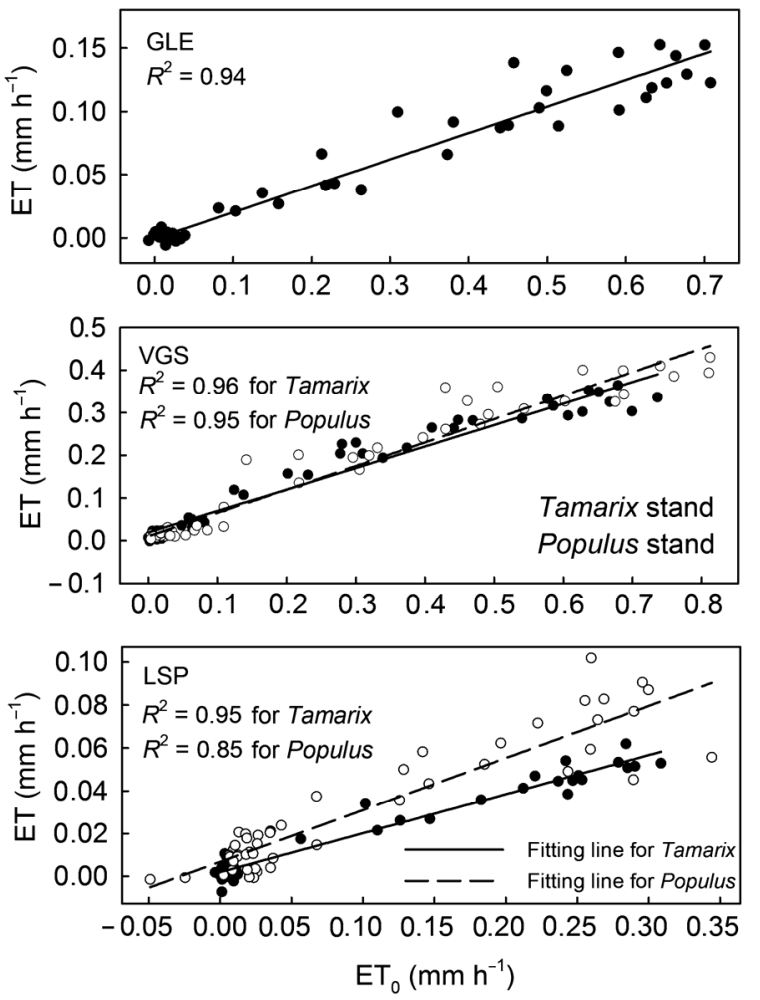

Figure 5 Linear relationships between hourly ET and hourly $\mathrm{ET}_{0}$ in three different phonological stages over the Tamarix stand and the Populus stand. The data in GLE was from May 17, 2013; the data in VGS was from July 19, 2013; the data in LSP was from October 12, 2013. $P<0.0001$.

corresponding atmospheric conditions. Every spring, under a rapid rise in temperature, $\mathrm{ET}_{0}$ began to increase rapidly, while the observed daily ET remained less than $0.1 \mathrm{~mm}$ until Tamarix began to sprout at the end of April (Figure 2). The high atmospheric evaporation demand $\left(\mathrm{ET}_{0}\right)$ did not lead to the increase in soil evaporation until plant germination. On the other hand, due to the hyper-arid climate, a dry sand layer without liquid water covers the soil surface, which produces great resistance to the soil evaporation from the soil layer below (Vervoort, et al., 2009). This is the physical explanation of the weak soil evaporation in hyperarid area.

Since the proportion of soil evaporation in the surface ET is little under hyper-arid climate, the spatial variation of ET of desert riparian forest would be controlled by vegetation LAI. The larger LAI, the higher ET. The same pattern was observed in arid regions of southwest USA (Sala et al., 1996). We analyzed the relationship of LAI and ET/ET ${ }_{0}$ in GLE and LSP for both Tamarix stand and Populus stand. According to the approximate method commonly used, the daily LAI values were set to be linearly increased with time in GLE, and linearly declined with time in LSP (Foley et al., 1996). The results showed that $\mathrm{ET} \mathrm{ET}_{0}$ was significantly linearly correlated with LAI (Figure 6). ET gradually increased with the increasing of LAI in the early period of growing season, and decreased gradually with the decreasing 

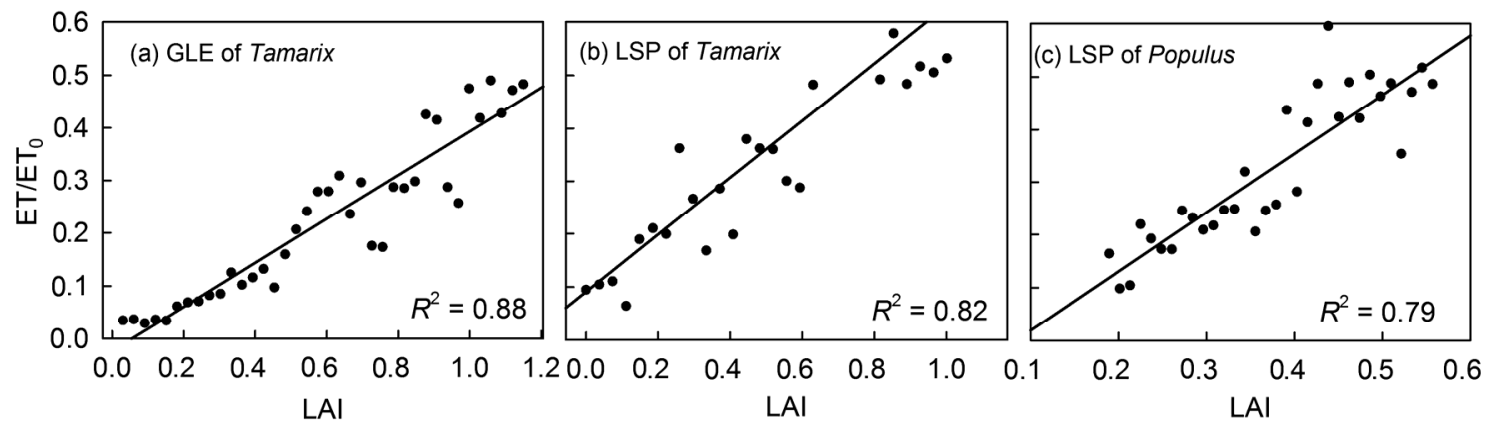

Figure 6 Linear relationships between leaf area index and ET/ET $_{0}$ in GLE of Tamarix spp. (a), LSP of Tamarix spp. (b), and LSP of Populus euphratica (c). $P<0.0001$.

of LAI in the late period of growing season. The linear correlation was more significant in GLE than in LSP. In LSP, physiological activity of leaves usually decreased with time, and also impacted the water consumption of plants other than the LAI. The significant linear relationships between $\mathrm{ET} / \mathrm{ET}_{0}$ and LAI in the early and late of growing season of the desert riparian forests could strongly supported our conclusions that the spatial variation of ET over the desert riparian forest zone was controlled by the vegetation LAI.

\subsection{Variations of the DWT and SWC and their roles}

Figure 7 shows 3-year temporal processes of DWT and SWC at depths of 3.0 and $5.0 \mathrm{~m}$ in the Tamarix stand. The gray area in Figure 7 represents the growing seasons during the observation periods. The DWT and the SWC at a depth of $5.0 \mathrm{~m}$ exhibited obviously seasonal variations, but the SWC at a depth of $3.0 \mathrm{~m}$ changed little. The DWT would drop after the onset of the growing seasons, and exhibits obviously diurnal fluctuation, which suggested groundwater consumption by plant water uptake; however, after midAugust, the DWT would arise, which indicated that the plant water consumption was less than the lateral seepage. This result was not caused by the decrease in plant water consumption (Figure 2) but by the increase in lateral seepage that resulted from the artificial water conveyance at this time every year. The SWC at a depth of $5.0 \mathrm{~m}$ would decline in growing seasons and revert to a maximum of 51\% when the DWT rose to a certain height or at the end of growing season under the dual control of capillary rise and root water uptake of the phreatophytic Tamarisk spp. As the representative of the temporal process at a depth of $3.0 \mathrm{~m}$, the SWC in the soil profile $1 \mathrm{~m}$ above the groundwater table did not exhibit clear temporal variations, which was in contrast to the SWC in deeper layers and the DWT, which suggested that the soil water in shallow layers hardly took part in the water exchange in the groundwater-soil-plant-air system, or the water movement from groundwater to surface ET in the groundwater-soil-plant-air system was in a steady state. Based on our observation results, under the deep groundwater depth, the contribution of the soil water in shallow layers to the surface ET was weak, and the main water source of ET was groundwater and the soil water in deeper layers.

The groundwater evaporation (ETg) in the growing season of 2012 was calculated using White's method, and compared with the corresponding ET. The comparison revealed that the seasonal variations in the estimated ETg and

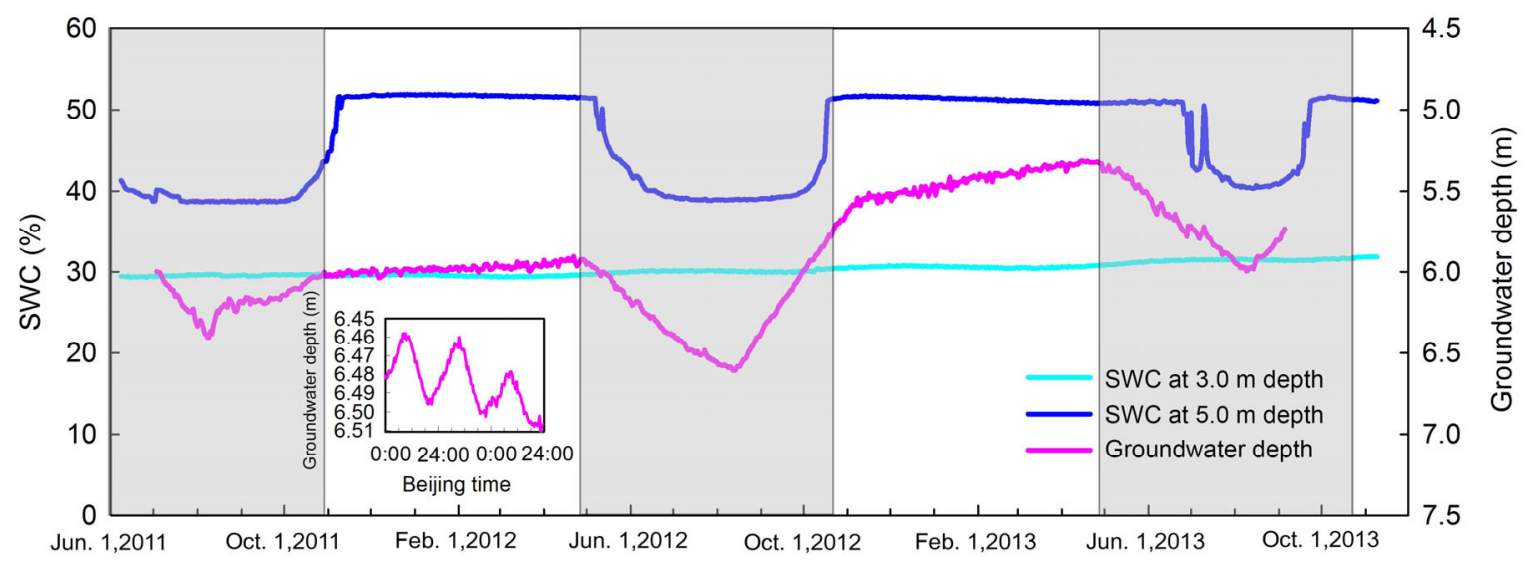

Figure 7 Variations of groundwater table and SWC at depths of 3.0 and $5.0 \mathrm{~m}$. The inset shows the diurnal fluctuation of groundwater table from July 11 to 13,2012 . The gray area refers to the growing seasons. 
the observed ET coincided (Figure 8). Only after obvious precipitation events, was the estimated ETg usually significantly less than the observed ET (Figure 8). This was due to the rainfall contribution to the surface ET other than the groundwater contribution. The ETg was $474.3 \mathrm{~mm}$ while the surface ET was $509.1 \mathrm{~mm}$ in the growing season of 2012. If subtracting the rainfall amount of $27.9 \mathrm{~mm}$ in this period, the amounts of ETg and ET were almost equal. The same phenomenon about the comparison between ETg and ET can be found in the growing season of 2013 in the Tamarix stand. The consistent seasonal variation and adjacent total amount between ETg and ET further indicated that the water source of ET was groundwater rather than soil water.

Because groundwater was the direct water source of plant water uptake, the ET process should be controlled by groundwater table changes. During our observation period, the groundwater table decline occurred in the earlier stages of the growing seasons, but the decline did not influence the ET processes. In the growing season of 2012, approximately $0.5 \mathrm{~m}$ of the groundwater table decline did not lead to the ET decreasing trend (Figure 9). This result indicated that the

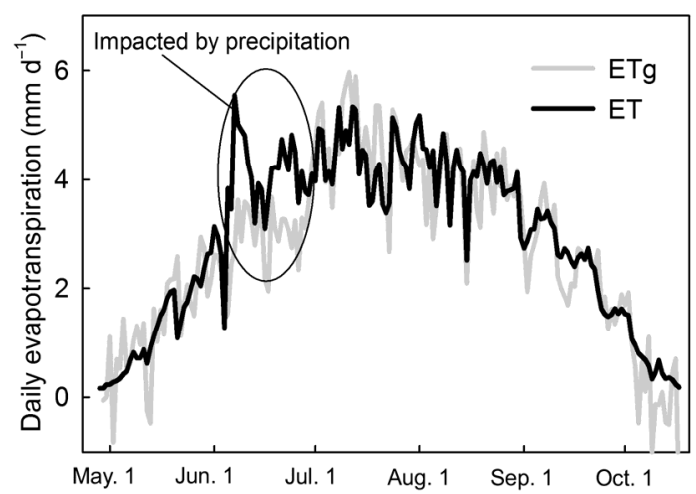

Figure 8 Comparison of seasonal courses between surface ET and groundwater ET (ETg) in the 2012 growing season of Tamarix spp. The large difference between ET and ETg appeared in June after two high precipitations occurred.

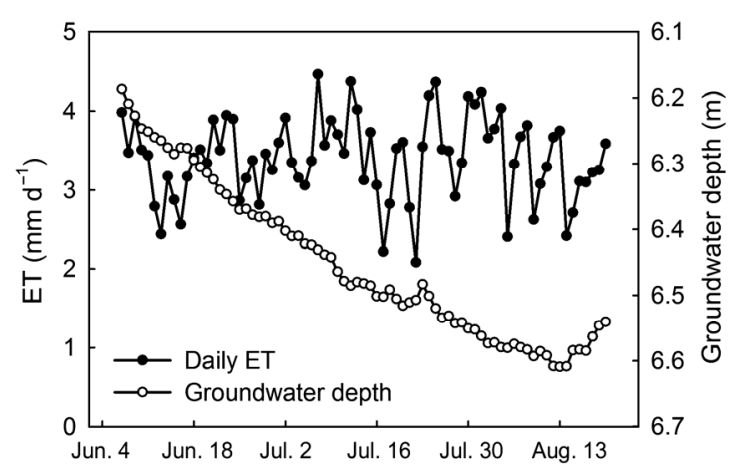

Figure 9 Effect of the groundwater table decline on surface ET over the Tamarix stand during the growing season of 2012. The groundwater table is the groundwater depth. The groundwater depth is the daily averaged data from the observed data. groundwater table decline must exceed a threshold value to produce effects on the surface ET, and also suggested that the observed Tamarix spp. community was not under water stress condition.

The DWT and SWC temporal processes indicated that it was the groundwater table rather than the soil water content that influenced the plant water uptake. The groundwater table is the crucial indicator to quantify the water stress of desert riparian forests, contrary to the mechanism on plant water stress in wet, semi-wet, and semiarid regions, in which soil water content is the critical factor influencing plant water stress. This role of groundwater table implies that quantifying the response of ET to the groundwater table change and its threshold is a critical requirement of the water resource management of the lower reaches of the inland rivers of China, which can improve our understanding of the hydrological threshold of desert riparian forests, and provide valuable scientific knowledge for effectively managing water resources of the inland rivers.

\section{Discussions}

\subsection{Key controlling mechanism on water cycling in lower reaches of inland rivers}

Anthropogenic oases have been developed along the middle reaches of the inland rivers of China. Irrigations in these oases causes the decreasing of channel incoming water to the lower reaches, even stream drying in many years (Shi, 2004; Liu et al., 2013). Consequently, flood is scarce in the lower reaches, and the water supplied for the soil water and plant water consumption is usually from groundwater rather than flood. Therefore, the water cycling in the lower reaches of the inland rivers of China is characterized as the process from the channel incoming water to groundwater, and ending in the form of surface ET. Because the environment in other lower reaches of the inland rivers of China is similar with that in the lower Tarim Basin with hyper-arid climate, sparse, narrow and long desert riparian forests that mainly consist of Tamarix spp. and Populus euphratica communications, based on our understanding of the water movements and ET processes in the lower Tarim Basin, we present a framework for describing the critical controlling mechanism on the water cycling in the lower reaches of the inland rivers of China (Figure 10).

Because of scarce precipitation, the incoming of water in the water cycling in the lower reaches is determined by runoff out of the middle reaches, which is controlled by climate change and anthropogenic activities in the upper and middle reaches of the inland rivers. Although influenced by the change of the internal climatic system, the ET amount in the lower reaches is mainly determined by the vegetation cover. According to the previous study, the vegetation cover was mainly influenced by the amount of channel incoming water (Tao et al., 2008; Li at al., 2013), 


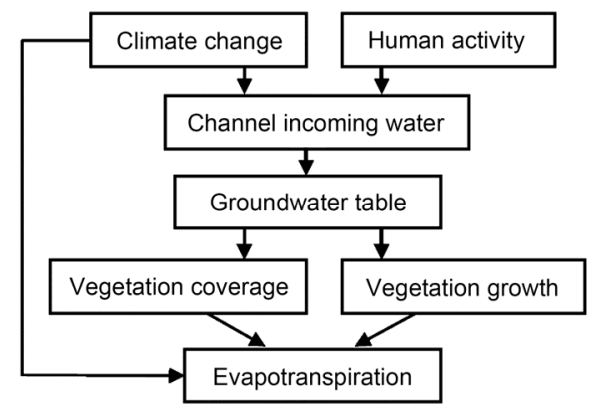

Figure 10 Generalized framework of water cycling process and its controlling mechanism in the lower reaches of the inland rivers in arid Northwest China.

and the change of the channel incoming water, controlled by the anthropogenic activities, is more intensive than the climate change. Therefore, the impacts of the anthropogenic activities on the water cycling in the lower reaches are much more than those of internal climatic system variation. In addition, climate change can significantly influence the runoff from the upper reaches of the inland rivers, and thus influences the amount of the incoming water to the lower reaches (Chen et al., 2008b). This is the main way by which climate change influences the water cycling in the lower reaches. On the other hand, the controls of anthropogenic activities on the channel incoming water are more and more intensive due to farming irrigation and population increase. For the most of the inland rivers of China, the amounts of incoming water to the lower reaches are generally controlled by the anthropogenic activities. In a sense, the water cycling in the lower reaches is a human-controlled water cycling, and the influences of climate change are increasingly weak as anthropogenic activities are becoming wider and deeper.

If the lower reaches of the inland rivers can be seen as a close system, after the incoming water enters the system, each process of water cycling in the system is rarely disturbed by anthropogenic activities. Groundwater is the key factor in the processes of the water cycling; it influences the soil water dynamics (Ridolfi et al., 2008; Laio et al., 2009), plant water uptake, and consequently the surface ET process. According to our results, the impacts of groundwater table to surface ET process consist of two aspects (Figure 10): (1) the differences of groundwater depths determine the spatial pattern and vegetation coverage (Zhu et al., 2012; Li et al., 2013) of desert riparian plants, in consequence, influence the amount of ET; and (2) the changes of groundwater table impact the ET processes by influencing plant growth and physiological activities. Because of little contribution of soil evaporation, the ET amounts in the lower reaches depend on water consumption characteristics and the coverage of plant species. The species and their water consumption characteristics are the results of evolution and adaptability of the plants to specific environment, therefore, the ET amounts are mainly determined by the coverage of plant species, which is further determined by the spatial pattern and changes of the groundwater table (Hou et al., 2007).

Revealing the relationship between the groundwater table and growth and spatial pattern of the desert riparian forests is vital for understanding the water cycling and its controlling mechanism in the lower reaches of the inland rivers. Although the relationships between groundwater depth and spatial pattern of desert riparian forests have been explored and revealed (Tao et al., 2008; Zhu et al., 2012), it is lack of the understanding of the impacts of groundwater dynamics on the surface ET processes. Through quantifying these impacts of groundwater dynamics, we can obtain valuable tools to adjust groundwater table through properly water resources allocations in the lower reaches. However, it is difficult to achieve this aim because there is little field environment to satisfy the related field observation and experiment. It will be a feasible way to resolve this problem using the numerical analysis based on processing mechanical models.

\subsection{A new method to estimate water requirements of desert riparian forests}

Reasonable estimation of the water requirements of the desert riparian forests is necessary for the water resources management of the inland rivers. Existing methods that have been proposed for estimating ecological water requirements or vegetation water requirements of the inland rivers (Hu et al., 2008) could not answer the two questions in water resources management of the inland rivers: (1) the spatial and temporal processes of the water requirements of the desert riparian forests; and (2) the trend of water requirements under different human's intervention. Additionally, water resource management agencies usually hope to know real-time water requirements and to predict water requirements in the future based on the real-time and forecasted weather data. The previously proposed methods of estimating water requirements cannot satisfy the practical demand of the water resources management agencies. Based on our understanding of the characteristics of water consumption and the controlling mechanisms of Tamarix and Populus forests in the lower Tarim River Basin, it is possible to develop a simple and practicable model of estimating water requirements of desert riparian forests in the lower reaches of the inland rivers for water resources management, which can use weather data, and can answer the above-mentioned two questions.

The water requirements of desert riparian forests are defined to be the regional ET of desert riparian forests without water stress, namely, the regional potential ET $\left(\mathrm{ET}_{\mathrm{p}}\right)$ under local climate and actual vegetation cover condition. Because of weak soil evaporation, under appropriate groundwater depth, the ET over desert riparian forests is determined by atmospheric conditions and vegetation status. The vegeta- 
tion status can also be divided into spatial distribution and plant physiological activities that could influence the amount and the process of ET, respectively. According to our results, ET is linearly related with $\mathrm{ET}_{0}$ (Figure 3), and LAI is linearly related with ET/ET ${ }_{0}$ (Figure 6). Further considering the influence of plant physiological factors to ET, this model can be expressed as

$$
\mathrm{ET}_{\mathrm{p}}=\alpha_{\mathrm{p}} \cdot \mathrm{LAI} \cdot K_{\mathrm{b}} \cdot \mathrm{ET}_{0},
$$

where LAI is the leaf area index; $\alpha_{\mathrm{p}}$ is a population-specific parameter, describing the structural trait of certain population; $K_{\mathrm{b}}$ is a species-specific parameter expressing the impact of species physiological activities on ET.

This model is a species-specific and spatially-explicit model, and it highlights the impact of spatial variations of vegetation cover (LAI). The model can be parameterized through the measurement of ET for different desert riparian forests under appropriate groundwater depth. The model runs through weather data, and can estimate the spatial difference of water requirements of desert riparian forest zone based on the LAI spatial distribution data. The model can also predict the water requirements under different vegetation restoration scenarios through setting different areas of species and their coverage. Therefore, this model can provide more practicable and wider references for water resources management of the inland rivers of China.

Because the water consumption characteristics of desert riparian forests of the inland rivers in the northwest of China are similar, the model presented here can be used to estimate water requirements of desert riparian forests in other inland rivers of China after parameterization of different desert riparian vegetation types through field measurement data.

\section{Conclusions}

In the lower reaches of the Tarim River under hyper-arid climate, ET over the desert riparian forests zone was weak in the non-growing season, and its seasonal variation in the growing season was consistent with plant phenology. The ET processes were influenced by atmospheric condition as well as plant phenology. Plant transpiration accounted for most of the surface ET, with soil evaporation weak and negligible. The spatial pattern of ET was determined by vegetation LAI. The more vegetation coverage, the higher LAI and ET amount, and vice versa. Groundwater table and its dynamics are crucial factors influencing ET over the desert riparian forests. Groundwater influenced the processes and amounts of ET by controlling the growth and spatial distribution of desert riparian forests. Contrary to the obviously seasonal variations of groundwater table, the soil water content in shallow layers did not exhibit temporal variations. Quantifying the water stress of desert riparian forests using groundwater table is more appropriate, rather than soil water content. Quantifying the response of ET to the groundwater table change and its threshold is a critical requirement of the water resource management of the lower reaches of the inland rivers of China.

The processes of ET over the observed Tamarix stand and the observed Populus stand were similar, but the water consumption of the well-grown Populus euphratica was higher than that of the well-grown Tamarix spp. Under the same LAI (LAI = 0.57), ET over the well-grown Populus stand was $4.52 \mathrm{~mm}$, while that over the well-grown Tamarix stand was $2.58 \mathrm{~mm}$.

These understandings of ET processes and their controlling mechanisms over the Populus stand and the Tamarix stand indicate that it is feasible to develop a simple and practicable model to estimate water requirements of desert riparian forests in arid regions by considering the vegetation coverage, plant growth and meteorological condition. This model can not only reveal and predict the temporal and spatial variations of water requirements of desert riparian forests using real-time or forecasting weather data, but also assess and direct the water resources managements by predicting the water requirements under different vegetation distributions and coverages. This model is proposed based on our understanding of ET processes over the observed desert riparian forests; its feasibility needs to be tested using more data.

This study was supported by the National Natural Science Foundation of China (Grant No. 41271050), and the National Basic Research Program of China (Grant No. 2010CB951002). We also thank Xiaobo Yi and Tao Du for their participation in the field work.

Abdurahman M, Kurban A, Ablat A, et al. 2008. Study on phenological characters of populus euphratica Oliv. in the lower reaches of the Tarim River. Arid Zone Res, 25: 525-530

Allen R G, Pereira L S, Raes D, et al. 1998. Guidelines for computing crop water requirements. FAO Irrigation and Drainage Paper No. 56. Roma, Italy, United Nations, FAO. 300

Bai Y Q. 1998. Studies on phenological patterns of the main shrubs in Yanchi sandy land. J Arid Land Resour Environ, 12: 82-86

Chen X, Huang Y, Qian J, et al. 2007. Simulation analysis on the regulation of overflow ecological water consumption in and areas-A case study in the Canmrik ecological area of the mainstream zone of the Tarim River. Sci China Ser D-Earth Sci, 50: 1-8

Chen Y N, Zhang X L, Zhu X M, et al. 2004. Analysis on the ecological benefits of the stream water conveyance to the dried-up river of the lower reaches of Tarim River, China. Sci China Ser D-Earth Sci, 47: 1053-1064

Chen Y N, Li W H, Xu H L, et al. 2003. The influence of groundwater on vegetation in the lower reaches of Tarim River, China. Acta Geog Sin, 58: 542-549

Chen Y N, Wang Q, Li W H, et al. 2006. Rational groundwater table indicated by the ecophysiological parameters of the vegetation: A case study of ecological restoration in the lower reaches of the Tarim River. Chin Sci Bull, 51: 8-15

Chen Y N, Hao X M, Li W H, et al. 2008a. An Analysis of the ecological security and ecological water requirements in the inland river of arid region. Adv Earth Sci, 23: 732-738

Chen Y N, Pan Z H, Hao X M, et al. 2008b. Periodic changes of stream flow in the last 40 years in Tarim River Basin, Xinjiang, China. Hydrol 
Process, 22: 4214-4221

Chen Y N. 2010. Study of the Ecohydrology in the Tarim River Basin of Xinjiang. Beijing: Science Press. 865

Fang K Y. 2001. The rise and decline and preservation of a green corridor along the lower reaches of the Tarim River. Contemp Chin Hist Stud, 8: $115-123$

Foley J A, Prentice I C, Ramankutty N, et al. 1996. An integrated biosphere model of land surface processes, terrestrial carbon balance, and vegetation dynamics. Glob Biogeochem Cycle, 10: 603-628

Hao X M, Li W H, Huang X, et al. 2010. Assessment of the groundwater threshold of desert riparian forest vegetation along the middle and lower reaches of the Tarim River, China. Hydrol Process, 24: 178-186

Hao X M, Chen Y N, Li W H, et al. 2008. Response of desert riparian forest vegetation to groundwater depth changes in the middle and lower Tarim River. Acta Geog Sin, 63: 1123-1130

Hao Y B, Wang Y F, Huang X Z, et al. 2007. Seasonal and interannual variation in water vapor and energy exchange over a typical steppe in Inner Mongolia, China. Agric For Meteorol, 146: 57-69

Hou P, Beeton R J S, Carter R W, et al. 2007. Response to environmental flows in the lower Tarim River, Xinjiang, China: Ground water. J Environ Manage, 83: 371-382

Hu G L, Zhao W Z, Xie G X. 2008. Advances on theories of ecological water requirements of vegetation in arid area. Adv Earth Sci, 23: $193-200$

Laio F, Tamea S, Ridolfi L, et al. 2009. Ecohydrology of groundwaterdependent ecosystems: 1 . Stochastic water table dynamics. Water Resour Res, 45: W05419

Li W H, Hao X M, Qin X W, et al. 2008. Ecological process of desert riparian forest communities and its hydrological mechanism of inland river basin in arid area. J Desert Res, 28: 1113-1117

Li W H, Zhou H H, Fu A H, et al. 2013. Ecological response and hydrological mechanism of desert riparian forest in inland river, northwest of China. Ecohydrology, 6: 949-955

Liu T, Fang H, Willems P, et al. 2013. On the relationship between historical land-use change and water availability: The case of the lower Tarim River region in Northwestern China. Hydrol Process, 27: 251-261

Liu C M. 2004. Study on the regional allocation of eco-environmental conservation and eco-environmental water requirement in the Northwest China. In: Qian Z Y, ed. Strategic Study on Allocation of Water Resources, Conservation of Eco-environment and Sustainable Development in Northwest China. Beijing: Science Press. 320

Loheide S P, Butler J J, Gorelick S. 2005. Estimation of groundwater consumption by phreatophytes using diurnal water table fluctuations: A saturated-unsaturated flow assessment. Water Resour Res, 41: W07030

Ridolfi L, D’Odorico P, Laio F, et al. 2008. Coupled stochastic dynamics of water table and soil moisture in bare soil conditions. Water Resour Res, 44: W01435

Sala A, Smith S D, Devitt D A. 1996. Water Use by Tamarix Ramosissima and associated phreatophytes in a Mojave Desert Floodplain. Eco App, 6: 888-898

Shi Y L. 2004. Study of desertification and utilizations of soil and water resources in Northwest China. In: Qian Z Y, ed. Strategic Study on Allocation of Water Resources, Conservation of Eco-environment and Sustainable Development in Northwest China. Beijing: Science Press. 444

Tao H, Gemmer M, Song Y D, et al. 2008. Ecohydrological responses on water diversion in the lower reaches of the Tarim River, China. Water Resour Res, 44: W08422

Vervoort R W, van der Zee S E A T M. 2009. Stochastic soil water dynamics of phreatophyte vegetation with dimorphic root systems. Water Resour Res, 45: W10439

Wang G X, Cheng G D. 2002. Water demand of eco-system and estimate method in arid inland river basins: A case study of Heihe River basin. J Desert Res, 22: 129-134

Wang G X, Zhang Y, Liu G M, et al. 2005. Water demand evaluation of riverside in arid inland river basin: The case of Heihe River basin. Acta Ecol Sin, 25: 2467-2476

Wang P, Yu J, Pozdniakov S P, et al. 2014. Shallow groundwater dynamics and its driving forces in extremely arid areas: A case study of the lower Heihe River in northwestern China. Hydrol Process, 28: 1539-1553

Wohlfahrt G, Haslwanter A, Hortnagl L, et al. 2009. On the consequences of the energy imbalance for calculating surface conductance to water vapour. Agric For Meteorol, 149: 1556-1559

White W N. 1932. Method of estimating groundwater supplies based on discharge by plants and evaporation from soil-Results of investigation in escalante valley. Tech Rep, Utah-US Geological Survey. Water Supply Paper, 659-A

Ye Z X, Chen Y N, Li W H. 2007. Ecological water demand of vegetation based on eco-hydrological process in the lower reaches of Tarim River. Acta Geog Sin, 62: 451-461

Zhang Y C, Yu J J, Wang P, et al. 2011. Vegetation responses to integrated water management in the Ejina basin, northwest China. Hydrol Process, 25: $3448-3461$

Zhu J, Yu J, Wang P, et al. 2012. Interpreting the groundwater attributes influencing the distribution patterns of groundwater-dependent vegetation in northwestern China. Ecohydrology, 5: 628-636 